\title{
RECEPTION: STRATEGIC POINT FOR USER ACCESS TO THE UNIFIED HEALTH SYSTEM ${ }^{1}$
}

\author{
Thaise Honorato de Souza², Maria Terezinha Zeferino ${ }^{3}$, Vivian Costa Fermo
}

\begin{abstract}
${ }^{1}$ Thesis results - Reception in the SUS user: strategies for access to network emergency care in perspective worker, presented to Programa de Pós-Graduação Multidisciplinar em Saúde - Mestrado Profissional, concentration area Emergency Department, linked to the Hospital Universitário, Universidade Federal de Santa Catarina (UFSC), in 2014.

${ }^{2}$ Master Professional Multidisciplinary in Health Programa de Pós-graduação Multidisciplinar em Saúde - Mestrado Profissional, UFSC. Florianópolis, Santa Catarina, Brazil. E-mail: thaisetise@yahoo.com.br

${ }^{3}$ Ph.D. in Nursing. Professor, Departamento de Enfermagem, Programa de Pós-Graduação Multidisciplinar em Saúde - Mestrado Profissional, UFSC. Florianópolis, Santa Catarina, Brazil. E-mail: terezinha.zeferino@ufsc.br

${ }^{4}$ M.Sc. in Nursing. Nurse in the Municipal Secretary of Health. Florianópolis, Santa Catarina, Brazil. E-mail: vivianfermo@hotmail. com
\end{abstract}

\begin{abstract}
This study investigated to understand how user embracement of users with acute illness or chronic worsened works, which has no scheduled service (spontaneous demand) from the perspective of workers of the reception service of health centers in a municipality in the southern region of Brazil. Descriptive exploratory qualitative study conducted in ten health centers in a municipality of Santa Catarina, Brazil. In data collection 17 workers from the reception of these health services were interviewed between January and March 2014. Thematic content analysis was performed. The results showed that user access does not occur as recommended by the Ministry of Health, due to weaknesses in the work process. Therefore, it is necessary to reorganize the work process, considering the reception as a strategic point in order to qualify the access of users to the Unified Health System.
\end{abstract}

DESCRIPTORS: Health services accessibility. User embracement. Health services. Health management. Unified Health System.

\section{RECEPÇÃO: PONTO ESTRATÉGICO PARA O ACESSO DO USUÁRIO AO SISTEMA ÚNICO DE SAÚDE}

RESUMO: Este estudo busca compreender como ocorre o acolhimento do usuário com quadro agudo ou crônico agudizado, que não possui atendimento agendado (demanda espontânea), na perspectiva dos trabalhadores que atuam na recepção de Centros de Saúde. Estudo qualitativo, exploratório-descritivo, realizado em dez Centros de Saúde de um município de Santa Catarina, Brasil. Na coleta de dados foram entrevistados, entre janeiro e março de 2014, 17 trabalhadores que atuam na recepção destes serviços de saúde. Para compreensão do material empírico foi realizada a análise de conteúdo temático. Os resultados demonstraram que o acesso do usuário não ocorre conforme o preconizado pelo Ministério da Saúde, devido a fragilidades na organização do processo de trabalho. Portanto, é necessário reorganizar o processo de trabalho, considerando a recepção como ponto estratégico, a fim de qualificar o acesso dos usuários ao Sistema Único de Saúde. DESCRITORES: Acesso aos serviços de saúde. Acolhimento. Serviços de saúde. Gestão em saúde. Sistema Único de Saúde.

\section{RECEPCIÓN: PUNTO ESTRATÉGICO PARA EL ACCESO DEL USUARIO EN SISTEMA ÚNICO DE SALUD}

RESUMEN: Este estudio objetivó comprender cómo es la recepción al usuario con cuadro agudo o crónico agravado, que no tiene consulta programada (demanda espontánea) desde la perspectiva de trabajadores que actúan en la recepción de Centros de Salud. Estudio cualitativo exploratorio descriptivo realizado en diez Centros de Salud de una ciudad de Santa Catarina, Brasil. Fueron entrevistados entre enero y marzo de 2014, 17 trabajadores de la que actúan en la recepción de estos servicios de salud. Para la comprensión del material empírico se llevó a cabo el análisis de contenido temático. Los resultados mostraron que el acceso del usuario no se produce según lo recomendado por el Ministerio de Salud debido a las deficiencias en la organización del proceso de trabajo. Por lo tanto, es necesario reorganizar el proceso de trabajo, teniendo en cuenta la recepción como punto estratégico para calificar el acceso de los usuarios al Sistema Único de Salud. DESCRITORES: Accesibilidad a los servicios de salud. Acogimiento. Servicios de salud. Gestión en salud. Sistema Único de Salud. 


\section{INTRODUCTION}

The universal and equal access to actions and health services is a right of all Brazilians, guaranteed by the Constitution since $1988 .{ }^{1}$ For the achievement of a service orientated to the needs of the population, access to health care in Brazil underwent changes and currently the Primary Health Care (PHC), which organizes, the Family Health Strategy (FHS), is the preferred entry point for the user of the Unified Health System (SUS). PHC is responsible for coordinating the care strategies of the population, being able to solve up to $85 \%$ of health problems, performing preventive, curative, rehabilitative services and health promotion. The study presents individual and collective actions, linking up with other health services and social facilities. When necessary, it should ensure the continuity of care in an integrated manner to direct users to other points of the Health Care Networks (HCN). ${ }^{2}$

It is noteworthy that the concept of PHC is recent, dating from the late twentieth century, but its philosophical underpinnings come from the development of medicine as science. In recent years, there have been several international conferences that have helped reinforce this strategy, which resulted in a renewed $\mathrm{PHC}$ as a health policy in many countries for greater access to services, better results, efficiency, lower costs and greater user satisfaction. ${ }^{3}$

In Brazil there are still weaknesses in the PHC which result in overcrowding in the hospital emergency services by users who could have their needs met in Health Centers (CS), but this does not occur due to : coordination difficulty between levels of care; the precarious process of coordination between the services; ignorance of the various points of attention by the PHC professionals; Low financing of the Unified health system (SUS); difficulty of cooperation between primary and secondary care professionals; incipient reception in the FHS; unconsolidated health promotion practices; deficiency in communication processes; difficult access to specialized care; ${ }^{4}$ excess demand; hegemonic biomedical model ; lack of empowerment and democratic and reflective spaces to reorganize the work process in health. ${ }^{5}$

To change this reality, PHC, in one of its strategies must organize its work process so that integrated programmatic and spontaneous actions can occur, ie: program and implement health promotion activities, disease prevention and prioritization of resolving the most frequent problems and health situations, considering the responsibility of solving assistance to spontaneous demand. ${ }^{6}$ The process of user embracement therefore emerges as a technology to increase access and implement PHC as the point of entry to the health system, meeting spontaneous demands, providing assistance to other levels, in a safe fashion, so that the principles of the Unified Health System (SUS) are upheld. ${ }^{5,7}$

In this sense, PHC also has the function to be responsible for the care of patients with acute or exacerbated chronic conditions, whose complexity is compatible with this level of assistance; and provide initial care to urgencies and emergencies, in an appropriate environment, until referral to other health care units is possible. In these cases, practicing user embracement with an assessment of risks and vulnerabilities by health professionals through the User Embracement with Classification and Risk Rating qualifies and gives security assistance. - $^{7-8}$

Attending to the spontaneous demands in a CS has the potential to improve the quality in the care that is provided, seeing as most of the time, health professionals have a connection with the patient and know their health history. For this reason, strategies and reformulation policies, in order to resolve the patients' difficulty in accessing this service should be implemented by managers and professionals in order to make the actions of PHC committed to comprehensive care.

Given the above, this study aims to understand the reception of the patient with an acute or exacerbated chronic condition, who has no scheduled appointment (spontaneous demand) from the perspective of workers who work at the reception of the CSs of the municipality of Santa Catarina, Brazil.

\section{METHOD}

An exploratory-descriptive study, qualitative in nature conducted in ten CSs in the same municipality where the research was done, belonging to the state of Santa Catarina, Brazil. For the organization of its territory coverage, the municipality distributed their health services into five health districts: Centre, Continent, East, North and South. The CSs were appointed by municipal management by counting the largest number of Family Health Strategy teams in each health district. The study participants consisted of 17 professionals selected randomly by raffle, who performed first contact with users at the reception of these services, with three operating in the North health district; three in the East; four at the Centre; three in the South; and four on the Continent.

Inclusion criteria of the study participants included: Workers with more than three months in the 
service; aged 18 years; performing the first contact with users in the selected health services. Exclusion criteria: being away from the workplace for a long period of time, for example, sick or sabbatical leave. In this sense, the workers were invited to participate in the study, and after acceptance, they signed the consent form and were identified with the letter " $\mathrm{T}$ " followed by a random numeral from 1 to 17 to ensure the anonymity of participants.

Data were collected through semi-structured interview and were recorded between January 28th and March $15^{\text {th }} 2014$. All interviews were transcribed for analysis purposes, which considered the guidelines according to $\mathrm{HCN}^{9}$ in light of the National Humanization Policy (NHP). ${ }^{7}$ The data were organized and analyzed based on the content analysis technique, and the following steps were used: pre-analysis, coding and categorization..$^{10}$ This study was approved by the Ethics Committee of the Universidade Federal de Santa Catarina (UFSC) under protocol No. 503 976, following the recommendations of resolution No. 466/2012 ${ }^{11}$ of the National Health Council.

\section{RESULTS AND DISCUSSION}

Among the workers who responded to this study, $13(76.47 \%)$ were female and four $(23.53 \%)$ were male. Regarding the level of schooling, seven $(41.18 \%)$ had complete higher education, three $(17.65 \%)$ incomplete higher education, two $(11.76 \%)$ had technical education and five $(29.41 \%)$ completed elementary school. Regarding the working status, $13(76.47 \%)$ were effective employees of the municipality, four $(23.53 \%)$ were connected to a nursing or administration internship. Among the effective employees of the municipality, eight $(47.06 \%)$ were administrative three $(17.65 \%)$ were community health workers, and one $(5.88 \%)$ was an oral health technician. Referring to time of service, $11(64.71 \%)$ professionals had between three months to two years of service and six (35.29\%) workers had between two and nine years of service.

From the participants' comments, two categories emerged from the empirical material: The reception in the process of user embracement in PHC; (Mis)Standardization in compliance with spontaneous demand by means of user embracement.

\section{Reception in the process of user embracement in Primary Health Care}

The employee who works at the front desk has a great role in the user access to the health system, and for the most part, is responsible for the first contact with the user. The NHP recognizes them as agents that are part of the reception process, part of a strategy to promote changes in the organization of the work process, which aims to ensure access and comprehensiveness in the health care of the SUS users. User embracement includes the reception of the users, being responsible for listening to their complaints, concerns and anxieties, imposing the necessary limits, ensuring resolute attention and coordination with other health services for continuity of care when necessary. ${ }^{7}$

The exclusion of users and the difficulty in accessing the system is identified in this study, considering that sometimes the workers who perform the first contact with those who seek the health center because of acute or worsened chronic condition, direct the user to other health services, even before a clinical assessment by a health professional.

If I see that the person is very ill, their blood pressure is low, they are pale and about to faint, I call someone immediately, regardless of where he lives. If I see that he or she is able to go to their health clinic. I guide the user to go to their health clinic in their vicinity (T11).

I work according to the schedule, I want to attend to all the patients who come here saying, 'Oh I'm feeling bad' 'I' $m$ bad'. I look in the schedule, there is no availability, I end up sending them to the UPA (T2).

Depending on the report, severity of the condition that the user appears to possess, their origin, the high demand of users seeking the service that day and the scarcity of available appointments to meet with the doctor, it is the worker who works at the front desk who decides if the user needs to be seen or not at that moment, or in other words, they triage the users rather than accepting the patient and allowing a more thorough evaluation of the clinical situation be done by a health professional skilled in this area. When the user leaves the health services without receiving adequate treatment or with an irresponsible and inappropriate referral, this means that the principles of SUS and the user rights were not upheld.

This reality can be associated with the working conditions in the CSs. A study conducted in 2010 with 96 professionals working in the same PHC unit and municipality, identified the existence of work overload, inadequate numbers of people to meet the demands, and the lack of materials, resources and supplies. ${ }^{12}$ To improve user access, municipal administration commitment is necessary to supply human and material resources, in order to increase the access of users to PHC. The population along 
with health professionals, may, through the Health Boards, claim resolution for these weaknesses.

Education is essential to break the barriers in access to health, as when instructed, users are able to enforce their rights. ${ }^{13}$ The Charter of User Rights rules that everyone has the right to the access of orderly and organized health goods and services, and access should start, preferably in PHC units near to their house. In urgent / emergency situations, these services should receive and take care of the person, and of necessary forward them to another service, due to the health status and clinical indication. These referrals should be done through documentation which includes the clinical data of the user, the reason for referral, the professional's name and registration number from the professional register, identification of the health service unit that received the user and the unit to which the patient is being referred to. ${ }^{14}$

Verbal referrals by workers at the front desk, without clinical evaluation of the user and without the certainty of resoluteness to the exposed demand, were noted.

Written, no. Who can do in writing is only the doctor or nurse, but we talk to them, we explain the situation that we do not have what a hospital has, and that it would be better for the person to go there, as in a case of a broken leg (T17).

Municipality Resolution implemented in March 2014, after the collection of the present study, establishes that the reception must receive the public, welcome them, provide general information about the service and direct them to the sectors of the health facility, according to protocols established by management prohibiting the release or referral of users with clinical demands to other services without prior evaluation of the FHS. In addition, it regulates that all referring done by the CS to other points of the HCN should be done by a ESF professional and should be recorded in medical records and made available to the user in writing , including the name, address and telephone number of the unit/service to which the patient is being referred to, including date and time of referral. ${ }^{15}$ This reality demonstrates that local management is committed to the implementation of strategies in order to improve the work process related to responsible referrals between the different points of the $\mathrm{HCN}$.

The occurrence of user referral to other health services by the reception worker is worrisome because the demand in question was not known by the ESF team, in order to commit to longitudinal and comprehensive care. It is necessary to involve the management and the health team in the qualification of these workers and in the performance of their duties,so that they participate in the user reception, listening to the users with spontaneous demands and then, with the knowledge about the services offered by CS, and the other areas of the $\mathrm{HCN}$ and the duties of the other team members, guide users to meet with professionals belonging to the FHS, who are responsible for clinical evaluation of acute or exacerbated chronic cases, and for referrals when necessary.

In some reports, the receptionist does his or her work as recommended, by welcoming the user and providing continuity of care from a health professional. However, these workers who work at the front desk, do not see user embracement as something procedural in which they participate in, but as an evaluation of the clinical setting, performed in an environment defined by a specific professional worker. This perception may reflect the work process which is implemented in the CSs, addressing the user embracement like triage through qualified listening.

Our policy here is to direct. If you don't have a scheduled appointment, the reception directs the user to the reception room with the technical nurse (T7).

I ask for the documents, check if they are registered, listen to the needs of the patient, and pass them on to meet with the nurse. If you are not registered, I do the registration. If you do not have documents or identification, I testify to the address and make a provisional registration (T9).

I forward the user to the nursing team in order to be evaluated. If they decide necessary, for urgent cases, they will fit in an appointment with a doctor or refer the user to the Emergency Unit (T11).

User embracement, when done as a triage and done at the front door of the service, can perpetuate the exclusion of users to SUS, hindering adherence to treatment plan, the bond and co-responsibility. Also, it is perceived by health professionals, as another task to be accomplished, among other PHC, causing work overload, fatigue, stress and team conflicts. ${ }^{5}$ The need of permanent education in services is evident, in order to empower the employee about what really constitutes the process of user embracement, what are its actors, the importance and appreciation of their role in this process, which is seen as a necessary tool for the user to access the health care system and exercise their citizenship.

Links between local services and assistance programs, access to the information system, the availability of electronic medical records, qualified human resources and low staff turnover, logical 
support, are considered supports for the realization of a good user embracement. User embracement, in the dimension of the reorganization of the health service, has requirements to strategically manage people and actions, resulting in an effective communication channel between service and user as well as the agility in offering actions and services through a professionally committed team. ${ }^{16}$ The CSs have information systems and electronic medical records, which enhance the quality of care, however, the creation and implementation of protocols to standardize care for spontaneous demands and unscheduled appointments is necessary to decrease the inequities in the provision of programs and services and for the increase of access and improving the quality of the PHN.

\section{(Mis)standardization in compliance with spontaneous demand by means of user embracement}

The criteria used by $\mathrm{PHC}$ in responding to spontaneous demands are, at times, the result of the priority given by the individual worker and the organizational difficulties of the work process in the service, at the expense of the user's needs and without following evaluation criteria objectives.The reception refers the user to the different professionals of the FHS, according to their subjective perception of the user's health status and the existence of a vacancy in the agenda of superior professional.

Patients with pain we knock on the doctor's door. Patients with shortness of breath are given priority to see the doctor before the scheduled patients and even before those that have passed, they need immediate care, but it is what I told you, it depends on the complaint that they present to us with, we resize, doctors and nurses (T4).

It would be interesting to have an emergency team that could meet outside these reception hours, patients who may be sick, you have patients who are sick at ten in the morning, all the doctors' have full schedules, you will not have a free doctor to see, you have to go through the technical team, depending on the urgency, a gap will be made in the agenda (T17).

It is important to highlight that the professionals who work at the front desk do not have health training and at no moment, were appointed the responsibility of performing risk and vulnerability assessment of the user with acute or acute exacerbation of a chronic complaint, in a standardized manner and by a health professional. Also the perception of the reception workers, was that the demand should preferably be met by medical professional.
In this sense, considering $\mathrm{PHC}$ as a member of the Emergency Care Network, increased access to care and to acute cases should be put in to place , considering the risk assessment and appropriate intervention for different diseases in order to offer care in a timely fashion and consequently reduce the number of preventable deaths and repeat admissions. ${ }^{17}$

A Brazilian study implemented a protocol for spontaneous care demands with clinical complaints in the FHS based on the Manchester Protocol and User Embracement with Classification and Risk Rating in Medical Ambulatory Care. After the user's arrival to the unit, they were brought to the assessment room to assess their health conditions and for risk classification to be performed. The user was then classified according to the severity of the case, by using different colors, which define the referral as follows: Black (patients needing emergency care and should receive immediate care in an Emergency hospital / Medical emergency service), red (presenting with grave health risks and require priority medical consultation), yellow (presenting with changes in vital signs, but without health risks. They should receive medical consultation without priority, being seen to after the scheduled patients), green (with recent or acute complaints, not exceeding 15 days, and without risk of injury to health. they should be evaluated by the nurse or forwarded for scheduling according to nursing definition) and blue (problems or complaints for more than 15 days, should also be assessed by the nurse or forwarded for scheduling according to nursing definition). ${ }^{18}$

From the adaption of this protoco ${ }^{18}$ the results showed that of the 2,639 patients who sought medical care and had gone through the User Embracement with Classification and Risk Rating, 1,691 patients $(63 \%)$ were treated and obtained resoluteness by the nursing staff, getting the green and blue rating. The remaining $948(35.85 \%)$ patients required medical attention, receiving the yellow classification, red and black, and of these, only a small portion $(0.15 \%)$ required care in the hospital emergency room. ${ }^{18}$

From the standardization of care and implementation flows within the CS, to allow proper assessment of risks and vulnerabilities to which the patient is exposed, many of the spontaneous demands can be decentralized from the doctor, which may contribute the end of the "consultation time for user embracement" and the increase in the resoluteness of PHC. It also facilitates and qualifies the work at the front desk which can direct the spontaneous 
demands of the users to health professionals, following an established direction and agreed between the team members, facilitating equal and humane access, and combating inequities and user exclusion.

In some CSs of this study, working for a specified period (08:00 to 17:00) and also attending other types of demand, such as programmed consultations, health education groups, School Health Program, meeting teams, among others, resulted in the existence of consultation hours for spontaneous demands, which usually occurs in the first hours of the morning and afternoon. This is because the professionals usually reserve these times in their schedules for this type of demand.

\section{We asked for staff to arrive at 8am or 1pm (T9).}

Usually the nurses put six appointments in the morning and the afternoon for user reception.. The rest is a regular schedule (T8).

There would be four spaces per day, two morning and two vacancies for later (T2).

In such cases, users who seek these services at other times of the day will only be seen if there is an availability in the schedule or if it is a situation with an imminent risk of death.

This work organization is incompatible with the principles of SUS, from submitting waiting users to situations which are often inhumane, seen in order of arrival, without any criteria and without guaranteed access due to the number of limited appointments. ${ }^{1}$ The unavailability of alternative appointments and the restriction of care are factors that determine the search for other services, should be the first step to be overcome to provide greater user satisfaction. ${ }^{17}$

In both scenarios the study was aimed at assistance to spontaneous demands with acute or exacerbated chronic conditions throughout all the operations of the units.

User embracement by the heal th professional occurs during the period that the clinic is open, there may or may not be the possibility to be seen by the doctor (T14).

There is no specific time given, because we do not know the extent of the person's need (T7).

In these places they understand that acute cases, urgencies and emergencies are unforeseen situations, which makes scheduling appointments impossible and which requires the team to perform planning strategies to meet this demand.

For this reason, performing qualified user embracement with risk and vulnerability assessment of spontaneous demands, is one of the strategies suggested by the Ministry of Health when it comes to spontaneous demand access in PHC. In order for the implementation of standardization of care to take place in a responsible manner, the team should be able to diagnose severe cases early, make the necessary support measures to stabilize the case and activate the more complex service when necessary, in order to properly continue treatment. ${ }^{1}$

When asked if there was some sort of standardization to facilitate unscheduled access to children, pregnant women, elderly and / or the physically disabled, the lack of established protocols in the service was highlighted. Spontaneous demand is met by the order of arrival and in some cases, the reception worker sets the priorities.

If it is a little baby, you go there and suddenly ask the doctor or nurse to take a look. The elderly have preference $[. .$.$] (T1).$

Look, if there are availabilities everyone will be seen, of course we need to see the child, the elderly, pregnant women, hypertensive, diabetic (T7).

Although there is no standardization in the priorities for assistance to spontaneous demands, it can be seen that the workers often give priority to cases that they deem to be more serious, and set the care of children, elderly and pregnant women as priorities. It should be noted that this grant of priority, the interest of each CS is not enough, because there are a number of specific laws that guarantee the right of the user to priority access to health services, such as the Statute of the Elderly, Children and Adolescents, among others, not allowing the priority of analysis due to convenience, makes standardizing these priorities necessary, avoiding differential treatment between one health unit and another.

The need for CSs to standardize the treatment of spontaneous demands is evident, there is evidence that user access to services occurs in many ways, from the professional conduct of the worker who is currently working upon the user's arrival: user referral to another service without clinical assessment by a health professional being performed by workers at reception; screening performed by reception that is forwarded on to the doctor or nurse, from subjective judgment; setting times to meet spontaneous demand; as well as attending to spontaneous demands by the FHS professional throughout the whole operation of the service.

As for the solvability of the emergency situations in the PHC, the study points out that professionals working in the FHS do not understand the emergency situation as their responsibility and 
thus carry out the referral as the only form of attention. The qualification of family health professionals working in emergency situations should be improved and updated through the proposal of permanent health education, preventing bringing patients to a more complex service unnecessarily due to the unpreparedness of these professionals. ${ }^{19}$ Starting with the understanding that the care for acute, chronic and emergency situations are part of their duties, the team can discuss ways of service reorganization in order to meet this demand effectively and in a resolute manner.

An international study corroborates this idea by pointing out that the doctors from the PHC have difficulties in managing users in emergency situations, making the development of a continuing education program necessary, as a strategy to qualify their professional performance as well as user assistance. ${ }^{20}$

It is worth noting that the municipality in the study shows commitment in adopting strategies that improve care in the PHC such as the implementation of the PHC services portfolio, an authorizing document that sets standards and guidelines for the operation of the teams and the PHC services, whose objectives are to improve the quality and contribute to the expansion of activities and services and reduce inequities. In its guidelines, qualified listening should be held in all the hours of operation and by all health professionals, and, on average, $50 \%$ of the agenda of doctors, nurses and dentists, during all shifts, should be appointed to attend spontaneous demands. As for the minimum activities of PHC professionals concerning spontaneous care demands; it is up to the technical nursing staff to attend to spontaneous demands; it is up to the nurse to attend spontaneous demand and the vulnerability and risk assessment; and it is up to the doctor and the dentist to attend to spontaneous demands, first visits to the Emergency Department, and, when necessary, referring the user responsibly to other units of the HCN.

\section{FINAL CONSIDERATIONS}

The worker who makes the first contact with the user at the CS reception has played a leading role in the user access to the unit's services and their referral to the other unit of the HCN. Despite the PHC already being implemented, unscheduled user access still does not occur as recommended, since it is not the reception's duty to send the user to other points in the network. The misleading conduct in this sector should be discussed among all workers and management units in order to discover the causes that have led to those working at the reception and to the attitudes that exclude the users from the entry point of SUS and thus create and implement strategies that change the work process, and qualify the work of the reception.

As PHC has numerous activities that make this a large and complex service, with scheduled and spontaneous demands, user embracement becomes a tool that provides user access. Risk and vulnerability assessment allows a holistic, fair and effective service. In the municipality of this study, shortly after this research, a Service Portfolio was implemented which calls for this type of service. It is necessary that the receptionist be recognized as himself/herself and also by other workers as part of the reception process and thus participate in the actions of permanent education regarding the topic.

There is a need for continuing education for the entire team involved at the reception in relation to the access of users with acute or exacerbated chronic conditions. And, after the reorganization of CSs in order to comply with current national and local public policies, the replication of this study is recommended in order to identify the potential achieved with the implementation of user embracement with risk and vulnerability assessment, and how this strengthened the CS reception as a strategic point for user access to SUS, referring to the FHS professional able to properly evaluate the clinical case without impinging on the user rights.

\section{REFERENCES}

1. Brasil. Constituição da República Federativa do Brasil de 1988, 5 de outubro de 1988. Brasília (DF): 1988.

2. Ministério da Saúde (BR). Portaria no 2.488, de 21 de outubro de 2011. Aprova a política nacional de atenção básica, estabelecendo a revisão de diretrizes e normas para a organização da atenção básica, para a estratégia saúde da família (ESF) e o programa de agentes comunitários de saúde (PACS). Brasília (DF): Ministério da Saúde; 2011.

3. Cruz AD, Ferregut JAN, Pérez YS, Cruz RR. Reflexiones sobre el desarrollo histórico social de la Atención Primaria de Salud. Rev Cubana Med Gen Integr [internet]. 2014 [cited 2015 Jul 10]; 30(2):255-67. Available from: http://scielo. sld.cu/scielo.php?script=sci_arttext\&pid=S086421252014000200011\&lang=pt

4. Rodrigues LBB, Silva PCS, Peruhype RC, Palha PF, Popolin MP, Crispim JA, Pinto IC, Monroe AA, Arcêncio RA. A atenção primária à saúde na coordenação das redes de atenção: uma revisão integrativa. Ciênc Saúde Coletiva. 2014; 19(2):343-52. 
5. Mitre SM, Andrade ELG, Cotta RM. Avanços e desafios do acolhimento na operacionalização e qualificação do Sistema Único de Saúde na Atenção Primária: um resgate da produção bibliográfica do Brasil. Ciênc Saúde Coletiva. 2012; 17(8):2071-85.

6. Tesser CD, Norman AH. Repensando o cuidado na Estratégia Saúde da Família. Saúde Soc. 2014; 23(3):869-83.

7. Ministério da Saúde (BR). Humaniza SUS: Política Nacional de Humanização (documento base para gestores e trabalhadores do SUS). $2^{\mathrm{a}}$ ed. Brasília (DF): Ministério da Saúde; 2004.

8. Ministério da Saúde (BR), Conselho Nacional de Saúde. Relatório final da $14^{\text {a }}$ Conferência Nacional de Saúde: todos usam o SUS: SUS na seguridade social: Política pública, patrimônio do povo brasileiro. Brasília (DF): Ministério da Saúde, 2012.

9. Brasil. Portaria $\mathrm{n}^{\circ} 4.279$, de 30 de dezembro de 2010. Estabelece diretrizes para a organização da Rede de Atenção à Saúde no âmbito do Sistema Único de Saúde (SUS). Diário Oficial da República Federativa do Brasil, 31 dez 2010. Seção 1.

10. Bardin L. Análise de conteúdo. Lisboa (PT): Edições Setenta; 2009.

11. Ministério da Saúde (BR), Conselho Nacional de Saúde. Resolução n. 466, de 12 de dezembro de 2012. Diretrizes e normas regulamentadoras para pesquisas envolvendo seres humanos. Diário Oficial da União 13 jun 2012; Seção 1.

12. Paese F, Sasso GTMD. Patient safety culture in primary health care. Texto Contexto Enferm [internet]. 2013 [cited 2015 Jul 10]; 22(2):302-10. Available from: http://www.scielo.br/pdf/tce/v22n2/v22n2a05

13. Sánchez G, Laza C, Estupiñán C, Estupiñán L. Barreras de acceso a los servicios de salud: narrativas de mujeres con cáncer de mama en Colombia. Rev Fac Nac Salud Pública [internet]. 2014 [cited 2015 Jul 10];
32(3):305-13. Available from: http://www.scielo. org.co/scielo.php?script=sci_arttext\&pid=S0120386X2014000300005\&lang=pt

14. Ministério da Saúde (BR). Carta dos direitos dos usuários. $3^{\mathrm{a}}$ ed. Brasília (DF): Ministério da Saúde; 2011.

15. Florianópolis. Portaria SS/GAB/ No 26/2014, de 14 de março de 2014. Diário Oficial Eletrônico do Município de Florianópolis [internet]. 14 mar 2015 [cited 2015 Mai 05]; Seção 1.. Available from: http:/ / www.pmf. sc.gov.br/arquivos/diario/pdf/14_03_2014_19.30.20. d9658a08f3f5ab39d3bef6929595fb78.pdf

16. Guerrero P, Mello ALSF, Andrade SR, Erdmann AL. User embracement as a good practice in primary health care. Texto Contexto Enferm [internet]. 2013 [cited 2015 Jul 10]; 22(1):. Available from: http: / / www.scielo.br/scielo.php?pid=S010407072013000100016\&script=sci_arttext\&tlng=pt

17. Ministério da Saúde (BR), Gabinete do Ministro. Portaria GM n. ${ }^{\circ} 1.600$, de 07 de julho de 2011. Reformula a Política Nacional de Atenção às Urgências e institui a Rede de Atenção às Urgências no Sistema Único de Saúde (SUS). Diário Oficial da União 12 jul 2011; seção 1.

18. Roncato PAZB, Roxo CO, Benites DF. Acolhimento com classificação de risco na estratégia saúde da família. Revista da AMRIGS. 2012; 56(4):308-13.

19. Farias DC, Celino SDM, Peixoto JBS, Barbosa ML, Costa GMC. Acolhimento e resolubilidade das urgências na Estratégia Saúde da Família. Rev Bras Educ Med. 2015; 39(1):79-87.

20. Damaris RP, Magalys MM, Julio RP, Ernesto PL. Identificación de necesidades de aprendizaje sobre atención básica de urgencias y emergencias médicas en la Atención Primaria de Salud. Educ Med Super [internet]. 2014 [cited 2015 Jul 10]; 28(1):15-25. Available from: http:/ / scielo.sld.cu/scielo.php? script=sci_ arttext\&pid=S0864-21412014000100004\&lng=es 